\title{
AIR BIOFILTRATION APPLIED TO ODOURS TREATMENT
}

Series Title: Handbook of Environmental and Waste Management Publisher: World Scientific Publishing Co, Singapore

Edited by

Prof. Yung-Tse Hung, Prof. Lawrence K. Wang, Prof. Nazih Shammas

Chapter

\section{AIR BIOFILTRATION APPLIED TO ODOURS TREATMENT}

Authored by:

Raquel Lebrero, ChemEng

Raúl Muñoz, Ph.D. ChemEng

Santiago Villaverde, Ph.D. Assoc.Prof. ChemE

Department of Chemical Engineering and Environmental Technology

University of Valladolid, Spain

Address: Faculty of Sciences, Paseo del Prado de la Magdalena s/n, 47005 Valladolid, SPAIN Phone: (34) 983423656 Fax: (34) 983423013

svillave@iq.uva.es 
AIR BIOFILTRATION APPLIED TO ODOURS TREATMENT

\begin{abstract}
Development of biological techniques for air pollution control has been triggered by the implementation of new health and safety guidelines, which are nowadays including odorous contaminants. These techniques have shown several advantages when compared with physicochemical processes; such as the lower energy requirements, capital and operating costs and easy maintenance and control. Biofiltration is now a well-known and extensively applied technology, with more than 7500 full-scale biofilters operating in Europe.
\end{abstract}

Key words: air pollution, biofiltration, bioscrubber, biotrickling filter, odour control 
AIR BIOFILTRATION APPLIED TO ODOURS TREATMENT

TABLE OF CONTENTS

1. INTRODUCTION

2. PHYSICO-CHEMICAL TECHNIQUES

3. BIOLOGICAL TREATMENT

Bioscrubbers

Biotrickling filters

Biofilters

Activated sludge systems

4. COMPARATIVE ANALYSIS OF TREATMENT TECHNOLOGIES REFERENCES 


\section{INTRODUCTION}

Until recently, solid and liquid contamination has been given priority since gaseous emissions posse less risk for human health and environmental ecosystems ${ }^{1}$. However, in the last decades, atmospheric contamination and, within it, odorous contamination has become an important issue for industries to deal with. This is due to the increasing people concern about the damages caused by these emissions (leading to an increasing number of public complaints) and the emergent legislation for their regulation ${ }^{1,2,3}$. In fact, more than half the complaints received by the environmental regulatory agencies worldwide concern malodours ${ }^{4}$.

Many industries produce odorous gases, from process industries, synthetic flavouring and painting factories, paper mills, refineries... to waste water and solid waste treatment plants, rendering plants, slaughterhouses, etc. ${ }^{5}$. These odorous emissions are a complex and variable mixture of chemical compounds which can contain both organic and inorganic compounds $s^{6,7,8,9}$, predominating sulphur compounds (especially $\mathrm{H}_{2} \mathrm{~S}$, in concentrations ranging from 5 to $50 \mathrm{ppm}$, and mercaptans), volatile organic compounds (VOCs: fatty acids, aromatic compounds, aliphatic and chlorinated hydrocarbons, terpenes, aldehydes and ketones, etc.), ammonia and, occasionally, nitrogen derivates (amines, indole, etc.). Thus, characterization of such a mixture is extremely difficult, not only because of the diversity of compounds but also because of their small concentrations, in the order of $\mu \mathrm{g} \mathrm{m}^{-3}$ range. This also poses a severe technological challenge to the state of the art odour abatement technologies ${ }^{7}$. Gas-liquid equilibrium is also an important parameter when dealing with odours, since odorous mixtures only become a problem when they are transferred to the atmosphere. This equilibrium is given by Henry's law: $\mathrm{C}_{\mathrm{gi}}=\mathrm{H}_{\mathrm{i}} \cdot \mathrm{C}_{\mathrm{li}}$. 
Although it has been demonstrated that usually odorous emissions are not toxic or a direct cause of disease, gaseous odorants emissions can affect quality of life, having a negative effect on human health; for example, they are responsible for nausea, headache, insomnia, loss of appetite, respiratory problems, irrational behaviour etc. $^{8,10,11}$. Besides, as stated before, odorous emissions contains VOCs, which, according to De Nevers ${ }^{12}$, are one of the priority atmospheric pollutants in terms of diversity and emissions volume (as an example, 16 tones of VOCs were emitted in 2006 in the United States) and some of them, such as benzene, toluene or formaldehyde (PTCLOU) are toxic, mutagenic or carcinogenic.

Odorous pollutants are not only a threat for human health and welfare, but also for the environment, since their presence in the atmosphere causes photochemical smog formation and particulate secondary contaminants ${ }^{12}$. Treatment of these emissions becomes, thus, necessary.

The adequate selection of a technique solution for an odour contamination problem must take into account the level of efficiency required, the type of odour source, the odorants nature and their concentration or the contaminated air flowrate among others. It is also important to point out that odour control techniques look not only at treatments but also at both odours generation prevention and release minimization.

These techniques can be grouped into different categories ${ }^{13}$ :

- Plant modifications for odour containment (covering sources, trapping odorants in the emission source, etc) or process amendments to avoid odorants formation.

- Impact reduction by diluting emissions with fresh air or employing masking or neutralizing agents, introduction of artificial barriers to limit odorants diffusion, etc. 
- Odorants treatment and elimination, implemented when odour emissions can not be avoided: oxidation, adsorption, chemical scrubbing, biofiltration, etc.

Treatment technologies are usually classified, according to their underlying principles, into physico-chemical and biological techniques. Generally, physical methods only recover pollutants and recycle them (by phase transfer such as absorption and adsorption or concentration techniques), whereas combustion, chemical/photochemical oxidation, biotechnologies and other methods achieve partial or total pollutants elimination. 